\title{
Inactivation of Icmt inhibits transformation by oncogenic K-Ras and B-Raf
}

\author{
Martin O. Bergo, ${ }^{1,2}$ Bryant J. Gavino, ${ }^{1}$ Christine Hong, ${ }^{1}$ Anne P. Beigneux,, 2 \\ Martin McMahon, ${ }^{3}$ Patrick J. Casey, ${ }^{4}$ and Stephen G. Young ${ }^{1,2,5,6}$ \\ ${ }^{1}$ Gladstone Institute of Cardiovascular Disease, San Francisco, California, USA \\ ${ }^{2}$ Cardiovascular Research Institute, University of California, San Francisco, California, USA \\ ${ }^{3}$ Cancer Research Institute, University of California, San Francisco Comprehensive Cancer Center, San Francisco, \\ California, USA \\ ${ }^{4}$ Department of Pharmacology and Cancer Biology, Duke University Medical Center, Durham, North Carolina, USA \\ ${ }^{5}$ Department of Medicine, University of California, San Francisco, California, USA \\ ${ }^{6}$ The Medical Service, San Francisco General Hospital, San Francisco, California, USA
}

Isoprenylcysteine carboxyl methyltransferase (Icmt) methylates the carboxyl-terminal isoprenylcysteine of CAAX proteins (e.g., Ras and Rho proteins). In the case of the Ras proteins, carboxyl methylation is important for targeting of the proteins to the plasma membrane. We hypothesized that a knockout of Icmt would reduce the ability of cells to be transformed by K-Ras. Fibroblasts harboring a floxed Icmt allele and expressing activated K-Ras (K-Ras-Icm $t^{\mathrm{fl} / \mathrm{fl} x}$ ) were treated with Cre-adenovirus, producing K-Ras-Icmt $t^{\Delta \Delta}$ fibroblasts. Inactivation of Icmt inhibited cell growth and K-Ras-induced oncogenic transformation, both in soft agar assays and in a nude mice model. The inactivation of Icmt did not affect growth factor-stimulated phosphorylation of Erk1/2 or Akt1. However, levels of RhoA were greatly reduced as a consequence of accelerated protein turnover. In addition, there was a large

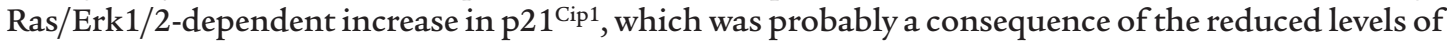
RhoA. Deletion of $\mathrm{p}^{2} 1^{\text {Cip } 1}$ restored the ability of K-Ras-Icm $t^{\Delta / \Delta}$ fibroblasts to grow in soft agar. The effect of inactivating Icmt was not limited to the inhibition of K-Ras-induced transformation: inactivation of Icmt blocked transformation by an oncogenic form of B-Raf (V599E). These studies identify Icmt as a potential target for reducing the growth of K-Ras- and B-Raf-induced malignancies.

J. Clin. Invest. 113:539-550 (2004). doi:10.1172/JCI200418829.

\section{Introduction}

Proteins that terminate with a carboxyl-terminal "CAAX" motif, such as the Ras and Rho proteins, undergo three sequential posttranslational processing events. First, the cysteine (i.e., the C of the CAAX sequence) is isoprenylated by protein farnesyltransferase (FTase) or geranylgeranyltransferase type I (GGTase I) (1). Second, the last three amino acids of the protein (i.e., the -AAX) are cleaved off by Rce1, an integral membrane protein of the ER (2). Third, the newly

Received for publication May 5, 2003, and accepted in revised form November 25, 2003.

Address correspondence to: Martin O. Bergo, Gladstone Institute of Cardiovascular Disease, PO Box 419100, San Francisco, California 94141-9100, USA. Phone: (415) 695-3774; Fax: (415) 285-5632;

E-mail: mbergo@gladstone.ucsf.edu.

Conflict of interest: The authors have declared that no conflict of interest exists.

Nonstandard abbreviations used: isoprenylcysteine carboxyl methyltransferase (Icmt); fibroblasts harboring a "floxed" Icmt allele and expressing activated K-Ras (K-Ras-Icmt $t^{\mathrm{fl} \mid \mathrm{l} / \mathrm{ll} x}$ );

farnesyltransferase (FTase); geranylgeranyltransferase type I (GGTase I); farnesyltransferase inhibitor (FTI); Cre-adenovirus (AdRSVCre); $\beta$-gal-adenovirus (AdRSVnlacZ); enhanced GFP (EGFP); mitogen-activated protein (MAP); polyinosinicpolycytidylic ribonucleic acid (pI-pC). exposed isoprenylcysteine is methylated by an ER membrane-bound methyltransferase, isoprenylcysteine carboxyl methyltransferase (Icmt) (3). These modifications render the $\mathrm{C}$ terminus of CAAX proteins more hydrophobic, facilitating binding to membranes (4-6).

The posttranslational processing of CAAX proteins has attracted interest because of the central role of mutationally activated Ras proteins in the development of cancer $(7,8)$. The enzymes that carry out the posttranslational modifications of CAAX proteins (i.e., FTase, GGTase I, Rce1, and Icmt) have been considered as potential targets for modulating the activity of the Ras proteins and for blocking the growth of Rasinduced malignancies. Farnesylation is critical for Ras activity (9), and farnesyltransferase inhibitors (FTIs) have shown promise in treating tumors, both in experimental animals $(10,11)$ and in humans $(12-17)$.

A potential drawback of the clinical use of FTIs is that $\mathrm{K}$-Ras and N-Ras-the isoforms most often mutated in human tumors-can be efficiently geranylgeranylated in the setting of FTI therapy $(18,19)$. This alternate prenylation of the Ras proteins could limit the efficacy of FTIs in the treatment of Ras-induced tumors. The existence of an alternate means for prenylation has led several groups to focus on the postisoprenylation steps mediated by Rce 1 and Icmt, since those steps are shared 
by farnesylated and geranylgeranylated CAAX proteins (6). We previously generated Rce1-knockout mice and found that they died quite late in gestation, after all of the major organ systems were formed (20). The Ras proteins in Rce1-deficient fibroblasts were mislocalized away from the plasma membrane, and the cells grew slightly slower than wild-type cells (20). More recently, we showed that the inactivation of Rce1 partially blocked transformation of cells by an activated form of H-Ras or K-Ras and sensitized transformed cells to the antiproliferative effects of an FTI (21).

The phenotype of Icmt deficiency in mice was more severe than Rce1 deficiency; an Icmt knockout caused grossly retarded growth during embryonic development and death at embryonic day 10.5-11.5 (22), possibly due to agenesis of the liver (23). Icmt deficiency causes mislocalization of the Ras proteins within cells, but virtually nothing is known about the effects of Icmt deficiency on cell growth and oncogenic transformation. To address these issues, we created a conditional ("floxed") Icmt allele, generated fibroblast cell lines, and then analyzed the consequences of inactivating Icmt.

\section{Methods}

Production of a conditional Icmt allele. To generate a conditional Icmt allele, exon 1 of Icmt along with upstream promoter sequences and parts of intron 1 were flanked with $\operatorname{lox} P$ sites. A $5^{\prime}$ arm of the gene-targeting vector (4 $\mathrm{kb}$ in length) was amplified from bacterial artificial chromosome DNA (24) with primers 5'-CTCTGTGCGGCCGCCTGTGTATAACTGTTTCCTTAGGTATG- ${ }^{\prime}$ and $5^{\prime}$ ACGACGGCGGCCGCCCGGCGACGCCGGCTCGGGAAGGGC-3' and cloned into the NotI site of pKSloxPNT (25). A 2.1-kb $3^{\prime}$ arm was amplified with primers $5^{\prime}$ ACGACGGCGGCCGCAGGGTAGGTGCACCAGGTACATTAGAACCG-3' ${ }^{\prime}$ and $5^{\prime}$-ACGACGGAATTCCTTCAGTTCTGGCCAGAAGATGTTGTCGAGCG- ${ }^{\prime}$ ' and cloned into the polylinker EcoRI site. A 717-bp fragment containing promoter sequences, exon 1 , and parts of intron 1 was amplified with $5^{\prime}$-ACGACTATCGATTTGAATGCGCAGGCCGGCCTTCGGGTTTCCC-3' and 5'-ACGACGGCGGCCGCATAACTTCGTATAATGTATGCTATACGAAGTTATGCCCCATCCCTGACTGATCGGTCCCTG-3', which contained a loxP site. That fragment was inserted between the polylinker ClaI and BamHI sites. The vector was linearized with $\mathrm{XhoI}$ and electroporated into 129SV/Jae ES cells. ES cells were screened by Southern blotting; the genomic DNA was cleaved with BamHI, and the blots were hybridized with a 292-bp 5'-flanking probe (24). Two targeted clones, each with a single integration event, were used to generate germlinetransmitting chimeric mice.

Primary fibroblasts were isolated from $\operatorname{Icm} t^{\mathrm{fl} \mid \mathrm{fl}}$ embryos on day 15.5 post coitum $(20,26)$. The cells were immortalized with a modified 3T3 protocol (26) or by transfecting the cells with E1A and activated human K-Ras (with a G12V activating mutation) (21, $27,28)$. For some experiments, the fibroblasts were also infected with a retrovirus encoding human K-Ras
(G12V) and a puromycin-resistance cassette. Experiments were performed with two different K-Ras-transfected Icm t $t^{\mathrm{fl} x / f \mathrm{~lx}}$ cell lines (A and B), unless otherwise indicated. To produce B-Raf-transformed cell lines, spontaneously immortalized Icm $t^{\mathrm{fl} / \mathrm{fl} x}$ fibroblasts were transfected with a retrovirus encoding an oncogenic form of human B-Raf (V599E) and a blasticidin-resistance cassette. Control cells were infected with a retrovirus encoding wild-type B-Raf. To inactivate Icmt (to produce $I c m t^{\Delta / \Delta}$ cells), Icmt $t^{\mathrm{fl} / \mathrm{fll}}$ cells were infected with $10^{8} \mathrm{PFU} / \mathrm{ml}$ of Cre-adenovirus (AdRSVCre). In parallel, control Icmt $\mathrm{fl}^{\mathrm{fl} / \mathrm{flx}}$ cells were treated with $10^{8} \mathrm{PFU} / \mathrm{ml}$ of a $\beta$-gal adenovirus (AdRSVnlacZ). The efficiency of Cre-mediated recombination was assessed with Southern blotting. All experiments with $I c m t^{\Delta / \Delta}$ cells were initiated three to four passages after the AdRSVCre infection. To produce mixed populations of $I c m t^{\mathrm{flx} / \mathrm{flx}}$ and $I c m t^{\Delta / \Delta}$ cells, Icm $t^{\mathrm{fl} / \mathrm{flx}}$ cells were infected with low titers of AdRSVCre $\left(10^{6} \mathrm{PFU} / \mathrm{ml}\right)$ and high titers $\left(10^{8} \mathrm{PFU} /\right.$ $\mathrm{ml}$ ) of AdRSVnlacZ (so that all of the cells in the dish would be infected with adenovirus).

Icmt activity assay. Icmt activity was measured with basehydrolysis assays with $S$-adenosyl-L- $\left[\right.$ methyl $\left.-{ }^{14} \mathrm{C}\right]$ methionine as the methyl donor and either $N$-acetyl-S-geranylgeranyl-L-cysteine or farnesyl-K-Ras as the substrate. The accumulation of "methylatable substrates" in cell extracts was quantified by measuring the methylation of proteins in cell extracts in the presence of recombinant Ste $14 \mathrm{p}$ (the yeast ortholog of Icmt) and S-adenosyl-L$\left[\right.$ methyl $\left.-{ }^{14} \mathrm{C}\right]$ methionine (24).

Analyzing fibroblast growth. Anchorage-dependent growth was assessed with a tetrazolium compound (MTS)-based cell proliferation assay (Cell Titer 96 AQueous One Solution Cell Proliferation Assay; Promega Corp., Madison, Wisconsin, USA). Icm $t^{\mathrm{fl} / \mathrm{fl} x}$ and $I c m t^{\Delta / \Delta}$ cells were seeded on 96-well plates (500 or 1,000 cells/well, $n=12$ wells/cell line, 1 plate per time point) and incubated at $37^{\circ} \mathrm{C}$. At various time points, $20 \mu \mathrm{l}$ of the MTS reagent ([3-(4,5-dimethylthiazol-2yl)-5-(3-carboxymethoxyphenyl)-2-(4-sulfophenyl)]$2 \mathrm{H}$-tetrazolium, inner salt) was added to each well and incubated for 2 hours at $37^{\circ} \mathrm{C}$. Cell density was quantified by analyzing absorbance at $490 \mathrm{~nm}$. The relative growth rates of $I c m t^{\mathrm{fl} / \mathrm{flx}}$ and $I c m t^{\Delta / \Delta}$ cells also were assessed with Southern blots to compare the relative intensities of Icmt $t^{\mathrm{flx}}$ and Icmt $t^{\Delta}$ bands at different passages. Cells were passaged 1:10 every 4 days; the intensities of bands on Southern blots were quantified with a phosphorimager.

Analyzing growth of hepatocytes in vitro. To fully inactivate Icmt in the liver (i.e., obtain nearly complete levels of recombination in the liver), Icm $t^{\mathrm{fl} / \mathrm{fl} \mathrm{fl}}$ mice harboring the inducible Mx1-Cre transgene (29) were injected intraperitoneally with polyinosinic-polycytidylic ribonucleic acid (pI-pC; Sigma-Aldrich, St. Louis, Missouri, USA) $(300 \mu \mathrm{g}$ every other day for a total of four injections). To generate mice with partial recombination in the liver (i.e., mice whose livers contained a mixture of $I c m t^{\mathrm{fl} / \mathrm{fl} x}$ and $I c m t^{\Delta / \Delta}$ hepatocytes), mice were given a 
single pI-pC injection $(200-500 \mu \mathrm{g})$. In the latter mice, the relative rates of $I c m t^{\mathrm{fl} / \mathrm{flx}}$ and $I c m t^{\Delta / \Delta}$ cell proliferation were assessed after a partial hepatectomy (30). To gain insight into the relative growth rates of $I c m t^{f \mathrm{~lx} / \mathrm{flx}}$ and $I c m t^{\Delta / \Delta}$ hepatocytes, Southern blotting was used to compare the ratio of $I c m t^{\mathrm{flx}}$ and Icmt ${ }^{\Delta}$ alleles at the time of partial hepatectomy and 10 days later, when liver regeneration was complete.

Analysis of anchorage-independent growth. The ability of K-Ras-Icmt $t^{\Delta / \Delta}$ and parental K-Ras-Icmt $\mathrm{fl}^{\mathrm{fl} / \mathrm{flx}}$ fibroblasts to form colonies in soft agar was analyzed in side-byside experiments. For these studies, K-Ras-Icmt $t^{\Delta / \Delta}$ fibroblasts were produced from K-Ras-Icm $\mathrm{fl}^{\mathrm{lx} / \mathrm{flx}}$ fibroblasts with AdRSVCre $\left(10^{8} \mathrm{PFU} / \mathrm{ml}\right)$. Control K-RasIcm $t^{\mathrm{fl}|\mathrm{fl}| \mathrm{x}}$ fibroblasts were infected with $10^{8} \mathrm{PFU} / \mathrm{ml}$ of AdRSVnlacZ. The K-Ras-Icmt $t^{\Delta / \Delta}$ and K-Ras-Icmt $t^{\mathrm{fl} / / \mathrm{Ilx}}$ fibroblasts (500-10,000 cells) were placed in medium containing $0.35 \%$ agarose and then poured onto 12 well plates containing a $0.70 \%$ agarose base. After the plates had been incubated at $37^{\circ} \mathrm{C}$ for $21-30$ days, the colonies were stained with 3-[4,5-dimethylthiazol-2yl]2,5-diphenyltetrazolium bromide (thiazolyl blue, MTT; Sigma-Aldrich) and photographed. The number of colonies was quantified with an image-processing tool kit in Adobe Photoshop 6.0 (21).

Assay of tumorigenicity in nude mice. To assess the relative capacities of K-Ras-Icmt $t^{\Delta / \Delta}$ and parental K-Ras-Icm $t^{\mathrm{flx} / \mathrm{flx}}$ fibroblasts to form tumors in nude mice, a mixed population of K-Ras-Icmt $t^{\mathrm{fl} / \mathrm{fl} x}$ and K-Ras-Icm $t^{\Delta / \Delta}$ fibroblasts was generated by treating K-Ras-Icmt $t^{\mathrm{fl} x / \mathrm{flx}}$ fibroblasts with a low-titer AdRSVCre $\left(10^{6} \mathrm{PFU} / \mathrm{ml}\right)$ as already described. Those cells $\left(5 \times 10^{6}\right)$ were injected into the flanks of 10-week-old female nude mice (strain NU/J Foxn $1^{n u}$; The Jackson Laboratory, Bar Harbor, Maine, USA). The relative capacities of the K-Ras- $I c m t^{f \mathrm{fl} / \mathrm{flx}}$ and the derivative K-Ras-Icm $t^{\Delta / \Delta}$ fibroblasts to contribute to tumor growth were assessed by comparing the ratios of Icm $t^{\mathrm{fl} x}$ and Icmt ${ }^{\Delta}$ alleles in the genomic DNA of the injected fibroblasts and in the tumors (harvested 21 days after injection).

Expression of buman ICMT in Icmt $t^{f l x}$ fllx and Icmt ${ }^{\Delta / \Delta}$ fibroblasts. K-Ras-Icmt $t^{\mathrm{fl} / \mathrm{flx}}$ fibroblasts were transfected with an expression vector (pcDNA6Myc/His-B; Invitrogen Corp., Carlsbad, California, USA) containing the human ICMT cDNA. Blasticidin-resistant colonies were picked and expanded. Two K-Ras-Icm t $\mathrm{fl}^{\mathrm{lx} / \mathrm{fl} \mathrm{lx} \text { ICMT }}$ cell lines were infected with AdRSVCre, generating $\mathrm{K}$-Ras-Icm $t^{\Delta / \Delta: I C M T}$ cell lines. The K-Ras-Icm $t^{\mathrm{fl} / \mathrm{f} / \mathrm{Ix}: \mathrm{ICMT}}$ and the derivative K-Ras-Icmt ${ }^{\Delta / \Delta \text { :ICMT }}$ cell lines expressed similar levels of Icmt enzymatic activity, indicating that most of the enzymatic activity in the cells was due to the human ICMT cDNA.

Subcellular fractionation to assess membrane targeting of the Ras proteins. S100 (cytosolic) and P100 (membrane) fractions of K-Ras-Icmt $t^{\Delta / \Delta}$ and K-Ras-Icmt $\mathrm{fl}^{\mathrm{lx} / \mathrm{fl} x}$ cells were prepared, and Ras proteins were immunoprecipitated as described (21). Western blots were performed with a K-Ras-specific mAb (Ab-1; Oncogene Research Products, San Diego, California, USA), a HRP-conjugated sheep anti-mouse IgG (Amersham Biosciences Corp., Piscataway, New Jersey, USA), and the Enhanced Chemiluminescence Kit (Amersham Biosciences Corp.).

Assessment of subcellular localization of $K$-Ras with an enhanced GFP-truncated (EGFP-truncated) K-Ras fusion protein. Icmt ${ }^{+/+}$and Icmt $t^{-1}$ fibroblasts were transfected with a plasmid coding for a fusion between EGFP and the C-terminal 20 amino acids of K-Ras (20). Transfections were carried out with SuperFect Reagent (QIAGEN Inc., Valencia, California, USA). Cells were fixed in $4 \%$ formalin 24-28 hours after transfection, mounted, and viewed with a Bio-Rad MRC-600 laser scanning confocal imaging system (Bio-Rad Laboratories Inc., Hercules, California, USA).

Coimmunoprecipitation of $p 21^{\text {Cip } 1}$ and cyclin A. Cyclin A was immunoprecipitated from $1.0 \mathrm{mg}$ of total cell protein from extracts of K-Ras-Icmt $t^{\Delta / \Delta}$ and K-Ras-Icm $t^{\mathrm{fl} x / \mathrm{flx}}$ cells with a polyclonal antibody (H-432; Santa Cruz Biotechnology Inc., Santa Cruz, California, USA) and resolved on 10-20\% SDS-PAGE gels. To detect cyclin A-associated p21 $1^{\mathrm{Cip} 1}$, immunoblots were then performed with an anti-p21 ${ }^{\text {Cip } 1}$ antibody (F-5; Santa Cruz Biotechnology Inc.).

Analysis of turnover of Rho and Ras proteins. To assess the impact of the Icmt gene inactivation on Ras and Rho turnover, K-Ras-Icmt $t^{\mathrm{fl} / \mathrm{fl} \mathrm{fx}}$ and the derivative $\mathrm{K}$ Ras-Icmt $t^{\Delta / \Delta}$ cells were seeded onto $60-\mathrm{mm}$ plates, grown overnight, and then grown for 2 hours in methionine-free medium. Cells were metabolically labeled with $0.8 \mathrm{mCi} \mathrm{L-}\left[{ }^{35} \mathrm{~S}\right]$ methionine and L- $\left[{ }^{35} \mathrm{~S}\right] \mathrm{cys}-$ teine (Pro-mix L- $\left[{ }^{35} \mathrm{~S}\right]$ in vitro cell labeling mix; Amersham Biosciences Corp.) for 2 hours. The cells were washed and incubated with regular medium supplemented with $4 \mathrm{mM}$ methionine and cysteine. Cells were harvested at different time points, and Rho and Ras proteins were immunoprecipitated from the extracts with pan-Rho [Anti-Rho (-A, -B, -C); Upstate Biotechnology Inc., Lake Placid, New York, USA] and pan-Ras (Ab-4; Oncogene Research Products) antibodies, respectively. The proteins were resolved on $10-20 \%$ SDS-PAGE gels that were subsequently treated with Amplify (Amersham Biosciences Corp.), dried, and exposed to film for 4-7 days.

Mitogen-activated protein (MAP) kinase signaling. Serum- and EGF-stimulated phosphorylation of the downstream Ras effectors Erk $1 / 2$ and Akt 1 was assessed by seeding $10^{5}$ nontransfected $I c m t^{\mathrm{fl} / \mathrm{flx}}$ and derivative $I c m t^{\Delta / \Delta}$ cells (i.e., no activated K-Ras) on 60$\mathrm{mm}$ dishes and then subjecting them to overnight serum starvation (in $0.5 \%$ serum). The next morning, medium containing $10 \%$ serum or $50 \mathrm{ng} / \mathrm{ml}$ human EGF (Sigma-Aldrich) was added to the cells. At various times after EGF stimulation, the cells were harvested and total cell extracts were analyzed by immunoblotting with antibodies recognizing phospho-Erk1/2 (phospho-p44/42 MAP kinase E10 mAb; Cell Signaling Technology, Beverly, Massachusetts, USA), phospho-Akt1 [(Ser 473)-R, polyclonal; Santa 


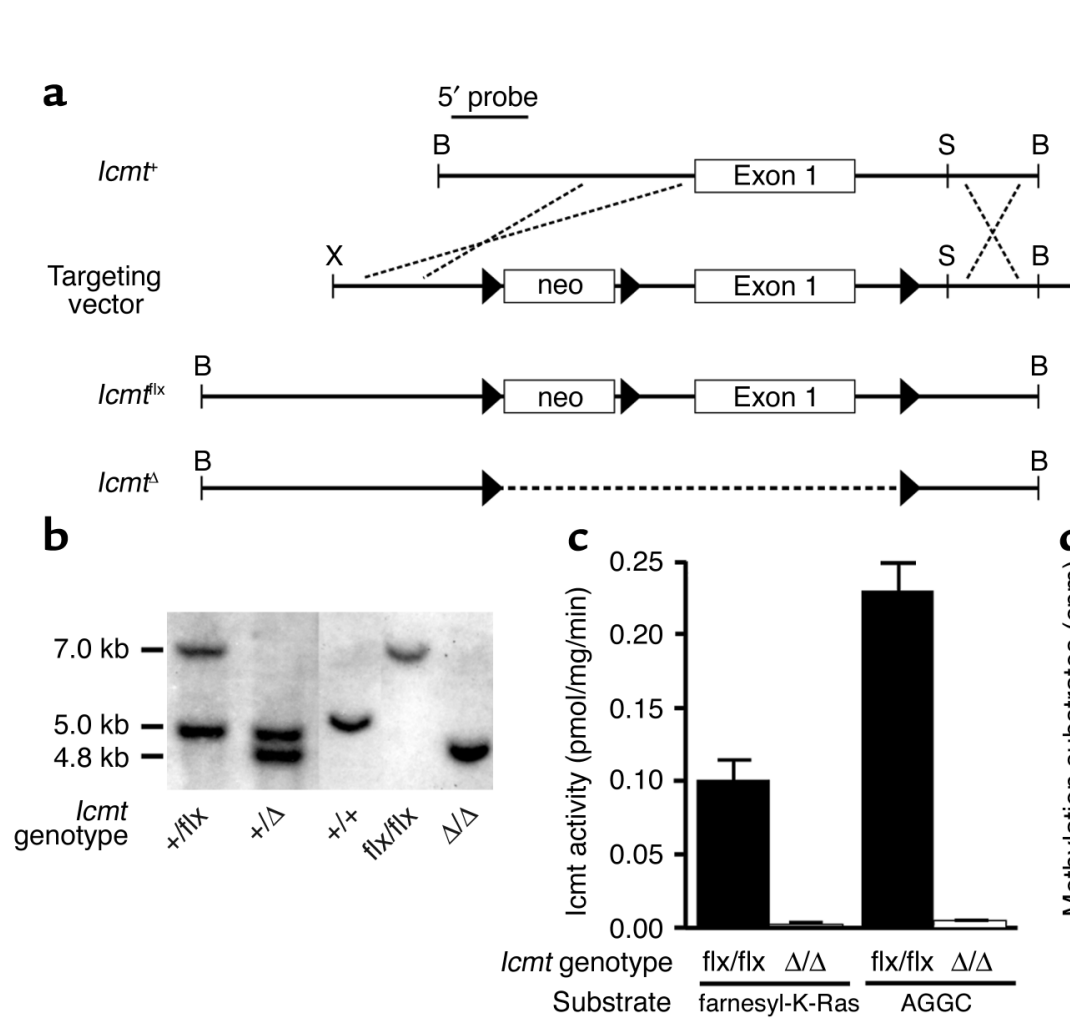

$\mathrm{BamHI}$

fragment

length

$(\mathrm{kb})$

5.0

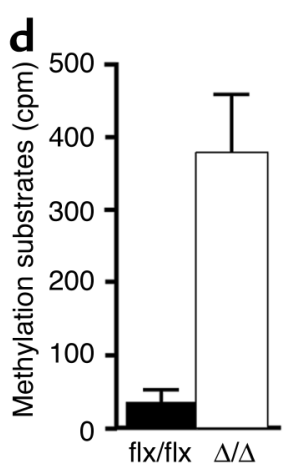

Figure 1

Generation and validation of a conditional $/ \mathrm{cm} t$ allele $\left(\mathrm{Icm} \mathrm{fl}^{\mathrm{fl}}\right)$. (a) A sequence-replacement gene-targeting vector designed to flank exon 1 and upstream sequences with IoxP sites. tk, thymidine kinase. (b) Southern blot identification of the $I \mathrm{cmt}^{+}$, Icmt $\mathrm{fl}^{\mathrm{fl} x}$, and Icmt $\mathrm{t}^{\Delta}$ alleles with BamHIcleaved genomic DNA and the $5^{\prime}$-flanking probe. (c) Icmt activity in extracts of $/ \mathrm{cm} t^{f \mathrm{fl} / \mathrm{fl} x}$ and $I \mathrm{~cm} t^{\Delta / \Delta}$ fibroblasts, as judged by a base-hydrolysis vapor-diffusion assay. Assays used S-adenosyl-L-[methyl-14 C]methionine as the methyl donor and either farnesyl-K-Ras or $\mathrm{N}$-acetyl-S-geranylgeranyl-L-cysteine (AGGC) as substrates. Bar graphs show the mean of two independent cell lines in two independent experiments. (d) Accumulation of $\mathrm{Icm}$ substrates in $I \mathrm{~cm}^{\Delta / \Delta}$ cells. Recombinant yeast Ste14p was added to extracts of $/ \mathrm{cm} t^{\mathrm{fl} / \mathrm{fl} \mathrm{x}}$ and $I \mathrm{~cm} t^{\Delta / \Delta}$ cells along with S-adenosyl-L- $\left[\right.$ methyl- $\left.{ }^{14} \mathrm{C}\right]$ methionine; methylation of protein substrates was measured with the base-hydrolysis vapor-diffusion assay.

Cruz Biotechnology Inc.], and total Erk1/2 (p44/42 MAP kinase, polyclonal; Cell Signaling Technology). Northern blotting and cDNA probes. Northern blots were performed with standard techniques (31) on total cellular RNA extracted with the TRI reagent (Sigma-Aldrich). A mouse Kras2 cDNA probe was amplified from a mouse liver cDNA library (CLONTECH Laboratories Inc., Palo Alto, California, USA) with forward primer 5 '-AAAGCGGAGAGAGGCCTGCTGAAAATG-3' and reverse primer 5'-ACCATAGGCACATCTTCAGAGTCC- $3^{\prime}$. A mouse RhoA (Ahra2) cDNA probe was amplified from the mouse liver cDNA library with forward primer 5'-ACTGGTGATTGTTGGTGATGGAGC-3' and reverse primer $5^{\prime}$-TCATTCCGAAGGTCCTTCTTGTTCCC-3'. A mouse p21 Cip1 (Cdkn1a) cDNA probe was amplified from the mouse liver cDNA library with forward primer $5^{\prime}$-AAAAGCACCTGCAAGACCAGAGGG- $3^{\prime}$ and reverse primer $5^{\prime}$-TTAAGTTTGGAGACTGGGAGAGGG-3'.

Generation of Cdkn1a-deficient Icmt fllifflx and Icmt $t^{\Delta / \Delta}$ cell lines. Male p21 Cip1-deficient mice (Cdkn1 $a^{-/}$) (32) (provided by Allan Balmain, University of California, San Francisco, California, USA) were bred with $I c m t^{\mathrm{fl} x / f \mathrm{~lx}}$

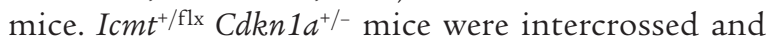

embryonic fibroblasts were harvested 15.5 days post coitum. Icmt $\mathrm{fl}^{\mathrm{fx} / \mathrm{fl} \mathrm{C}} \mathrm{C} \mathrm{dkn} 1 \mathrm{a}^{-/-}$spontaneously immortalized fibroblasts were infected with a retrovirus expressing the activated human K-Ras. K-Ras-Icmt ${ }^{\mathrm{fl} / \mathrm{flx}} \mathrm{Cdkn1a^{-/ }}$ fibroblasts were treated with AdRSVCre $\left(10^{8} \mathrm{PFU} / \mathrm{ml}\right)$ to generate K-Ras-Icmt ${ }^{\Delta \Delta} \mathrm{C} d k n 1 a^{-/-}$cells. Control K-Ras$I c m t^{\mathrm{fl} \times / \mathrm{fl} x} \mathrm{Cdkn} 1 \mathrm{a}^{-/}$fibroblasts were treated with AdRSVnlacZ $\left(10^{8} \mathrm{PFU} / \mathrm{ml}\right)$.

\section{Results}

Creation of Icmt-deficient fibroblast cell lines. To assess the importance of Icmt for cell growth and Ras transformation, we created a conditional Icmt-knockout allele in which exon 1 and upstream promoter sequences were flanked by loxP sites (Figure 1a). Two independent ES cell lines (each with a single neo integration) were used to create chimeric mice, which were bred to produce heterozygous mice $\left(I c m t^{+/ f \mathrm{fl}}\right)$. When $I c m t^{+/ f \mathrm{~lx}}$ mice were intercrossed, homozygous mice (Icmt $\left.t^{\mathrm{fl} x / \mathrm{flx}}\right)$ were born at the predicted mendelian frequency and were fertile and healthy. Fibroblasts from $I c m t^{\mathrm{fl} x / \mathrm{flx}}$ embryos were immortalized as described in the Methods section. Cre-mediated excision of the floxed segment of Icmt resulted in the production of Icmt $t^{\Delta / \Delta}$ cells 

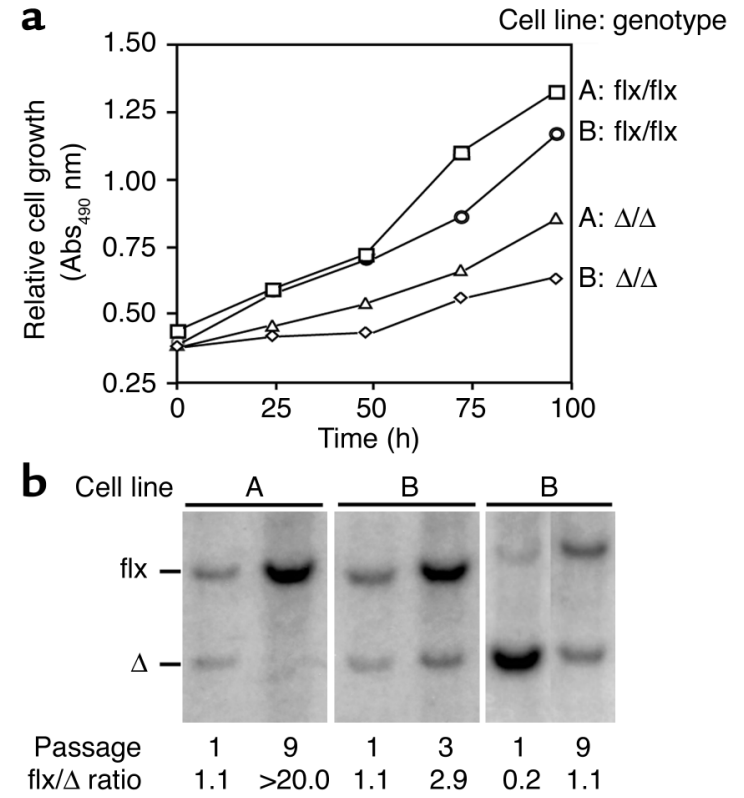

C

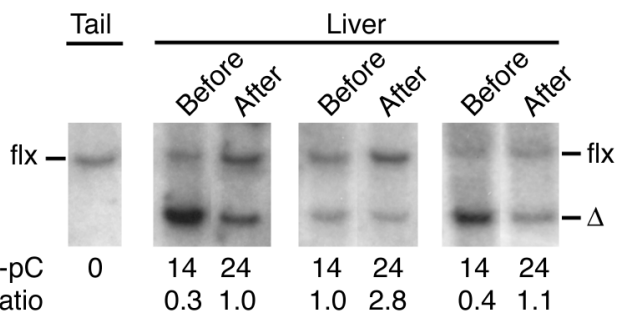

(Figure $1 \mathrm{~b}$ ). Not surprisingly, Icmt $t^{\Delta / \Delta}$ cells exhibited both a complete absence of Icmt enzymatic activity (Figure 1c) and a substantial accumulation of Icmt protein substrates (Figure 1d).

Icmt-deficient fibroblasts grow slowly. The inactivation of Icmt in immortalized fibroblasts reduced cell growth by $40-60 \%$ under routine cell culture conditions (anchoragedependent growth) (Figure 2a). To further examine the consequences of "switching off" Icmt, we produced mixed populations of $I c m t^{\mathrm{fl} / / \mathrm{flx}}$ and $I c m t^{\Delta / \Delta}$ cells by treating Icmt $\mathrm{fl}^{\mathrm{fl} / \mathrm{flx}}$ cells with low titers $\left(10^{6} \mathrm{PFU} / \mathrm{ml}\right)$ of AdRSVCre and high titers $\left(10^{8} \mathrm{PFU} / \mathrm{ml}\right)$ of AdRSVnlacZ (so that all of the cells were infected with an adenovirus). We then initiated competitive growth experiments to define the relative growth rates for $I c m t^{\mathrm{fl} \times / \mathrm{flx}}$ and $I c m t^{\Delta / \Delta}$ cells. For this, Southern blots were used to assess the ratio of the 7.0-kb Icmt $t^{\mathrm{fl}} \mathrm{band}$ and the $4.8-\mathrm{kb} I c m t^{\Delta}$ band (Figure $2 \mathrm{~b}$ ). If the Icmt inactivation had no effect on cell growth (i.e., if there were no differences in the competitive fitness of Icm $t^{\mathrm{fl} / \mathrm{flx}}$ and $I c m t^{\Delta / \Delta}$ cells), one would expect that the Southern blots would reveal stability-at different passages-in the relative intensities of the Icm $t^{\mathrm{flx}}$ and Icmt ${ }^{\Delta}$ bands. This was not the case. In each experiment, the ratio of the Icm $t^{\mathrm{fl}} \mathrm{x}$ band to the Icmt $t^{\Delta}$ band increased in later passages, indicating a competitive growth advantage of the parental $I c m t^{\mathrm{fl} / \mathrm{flx}}$ cells over the Icmt $t^{\Delta / \Delta}$ cells (Figure 2b).

Inactivating Icmt also interfered with the growth of hepatocytes in vivo. We bred Icm $\mathrm{fl}^{\mathrm{fl} / \mathrm{fl} \mathrm{x}}$ mice with mice harboring the inducible Mx1-Cre transgene and then

\section{Figure 2}

Analyzing the effect of $1 \mathrm{~cm} t$ inactivation on cell growth. (a) Anchorage-dependent growth of $/ \mathrm{cm} t^{\mathrm{fl} / \mathrm{fl} \mathrm{lx}}$ and $/ \mathrm{cm} t^{\Delta / \Delta}$ cells. Equal numbers of immortalized $I c m t^{f \mid \mathrm{l} / \mathrm{fl} x}$ cells and the derivative $I \mathrm{~cm} t^{\Delta / \Delta}$ cells (lines A and B) were plated onto 96 -well plates ( $n=12$ wells per cell line), and cell growth was assessed with the Cell Titer 96 AQueous One Solution Cell Proliferation Assay (Promega). (b) Southern blots illustrating the increase in the ratio of $1 \mathrm{~cm}^{\mathrm{flx}}$ to $1 \mathrm{~cm} \mathrm{t}^{\Delta}$ bands during the growth of a mixed population of $/ \mathrm{cm} t^{\mathrm{fl} / \mathrm{flx}}$ and $/ \mathrm{cm} t^{\Delta / \Delta}$ cells. Mixed populations of $I c m t^{f|l| f \mid x}$ and $I c m t^{\Delta / \Delta}$ cells were passaged at a 1:10 ratio every 3 days. DNA was harvested and analyzed with Southern blots at the indicat-

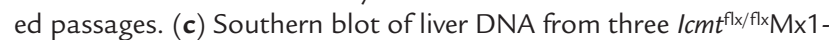
Cre mice before and after hepatocyte proliferation, which was induced by a partial hepatectomy. The ratio of $/ \mathrm{cm}^{\mathrm{flx}}$ to $/ \mathrm{cm} \mathrm{t}^{\Delta}$ band intensity increased after liver regrowth, indicating that $/ \mathrm{cm} t^{\mathrm{fl} / \mathrm{fl} \times \mathrm{h}}$ hepatocytes contributed more to liver regrowth than the $1 \mathrm{~cm} \mathrm{t}^{\Delta / \Delta}$ hepatocytes. Quantification of data from five mice revealed that the $1 \mathrm{~cm} t^{\mathrm{fl} x} / \mathrm{Icm} \mathrm{t}^{\Delta}$ ratio increased $201 \% \pm 26 \%$ after liver regeneration $(P<0.01)$.

administered a single intraperitoneal injection of $\mathrm{pI}-\mathrm{pC}$. A single pI-pC injection causes incomplete recombination in the liver; thus, the livers of these mice contained a mixed population of $I c m t^{\mathrm{fl} x / \mathrm{flx}}$ and $\operatorname{Icm} t^{\Delta / \Delta}$ hepatocytes. Two weeks later, we performed a partial hepatectomy, which triggers hepatocyte proliferation. To gauge the relative capacities of $I c m t^{\mathrm{fl} / \mathrm{flx}}$ and $I c m t^{\Delta / \Delta}$ hepatocytes to contribute to liver regeneration, we used Southern blots to measure the ratio of the 7-kb Icmt $\mathrm{fl}^{\mathrm{ll}}$ band to the $4.8-\mathrm{kb} I c m t^{\Delta}$ band in liver genomic DNA, both at baseline (at the time of the partial hepatectomy) and 10 days later when liver regeneration was complete. After liver regeneration, the ratio of the Icm $t^{\mathrm{fl}}$ band to the Icmt $t^{\Delta}$ band invariably increased, indicating that $I c m t^{\mathrm{flx} / \mathrm{fl} x}$ hepatocytes contributed more than the $\operatorname{Icm} t^{\Delta / \Delta}$ hepatocytes to liver regrowth (Figure $2 c ; P<0.01$, $n=5$ ). This difference could not be attributed to hepatocyte death due to the Icmt knockout. By treating $I c m t^{\mathrm{fl} x / \mathrm{flx}}$ mice with four intraperitoneal injections of $\mathrm{pI}$-pC, we readily generated mice in which Cre-mediated recombination in the liver was virtually complete. In those mice, plasma transaminases remained normal, and there was no histological evidence of hepatocyte necrosis (not shown).

Inbibition of K-Ras transformation in Icmt-deficient cells. Icm $t^{\mathrm{fl} x / \mathrm{fl} \mathrm{x}}$ fibroblasts that had been transfected with an activated form of K-Ras (K-Ras-Icmt $t^{\mathrm{fl} / \mathrm{fl} x}$ ) exhibited a transformed phenotype, forming numerous colonies in soft agar (Figure 3a). To assess the consequences of Icmt deficiency on K-Ras transformation, we then used AdRSVCre to inactivate Icmt in the K-Ras-Icmt $t^{\mathrm{fl} / \mathrm{fl} \mathrm{x}}$ cells, producing K-Ras-Icmt $t^{\Delta / \Delta}$ cell lines. In six independent side-by-side experiments, the K-Ras-Icmt ${ }^{\Delta / \Delta}$ cells yielded 90-95\% fewer colonies in soft agar than the parental K-Ras-Icmt $t^{\mathrm{fl} / \mathrm{fl} \mathrm{x}}$ cells (Figure 3, a and b, $P<0.0001$ ). When these experiments were repeated with K-Ras-Icmt $t^{\mathrm{fl} / \mathrm{fl} x}$ cells that expressed a human ICMT cDNA, AdRSVCre inactivation of the mouse Icmt gene had no detectable effect on colony growth (Figure 3 , a and b, $n=$ three independent experiments, $P=0.63$ ). Thus, inactivation of Icmt strikingly inhibited the ability of K-Ras-trans- 

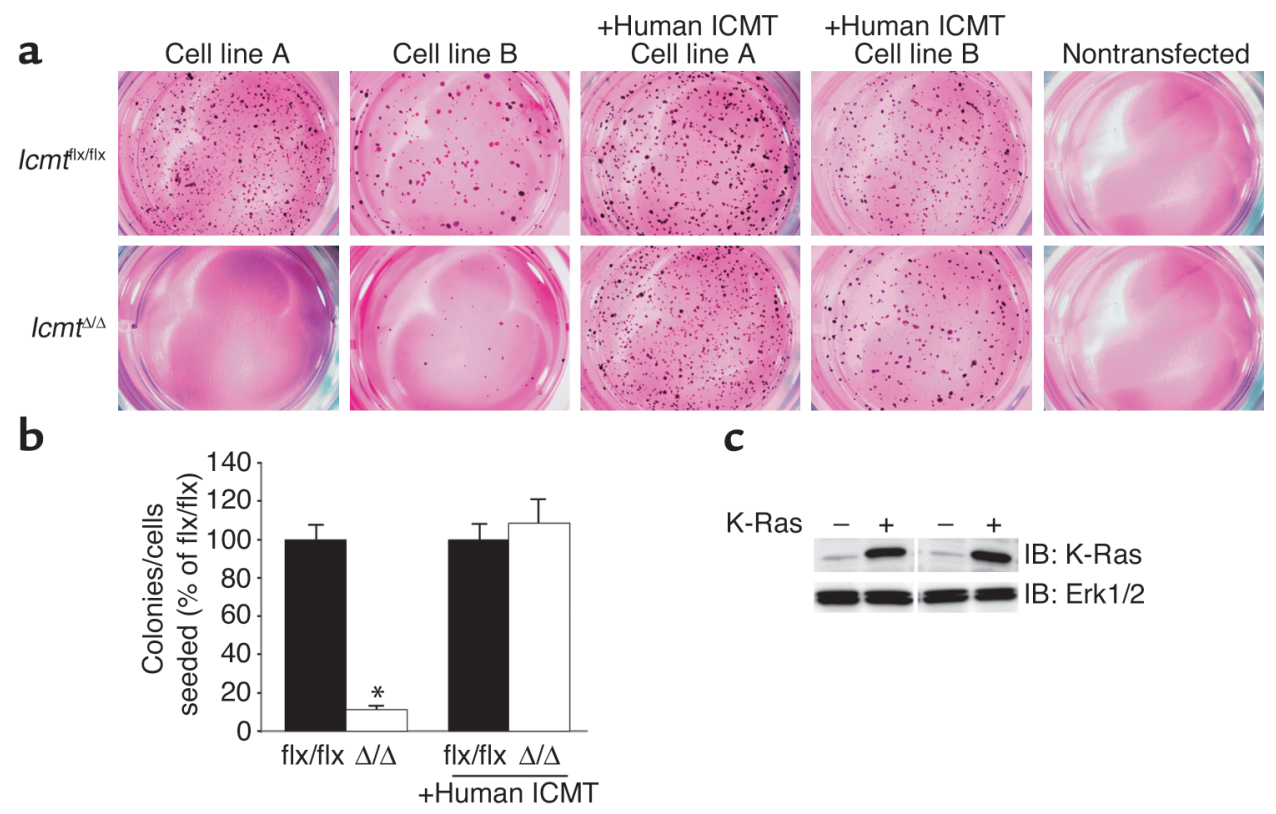

K-Ras

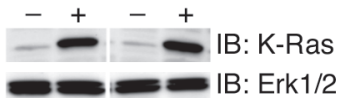

Figure 3

Reduced capacity of K-Ras-transfected Icmt-deficient fibroblasts to form colonies in soft agar. (a) K-Ras-Icmt $\mathrm{fl}_{\mathrm{f} / \mathrm{fl} \mathrm{x}}$ and derivative K-Ras-Icmt $t^{\Delta / \Delta}$ fibroblasts (2,000 cells of each) were mixed with $0.35 \%$ agarose and poured onto plates containing a $0.70 \%$ agarose base. Colonies were stained and photographed 21 days later. Nontransfected cells (i.e., no activated K-Ras) did not form colonies in soft agar. (b) Bar graph illustrating the number of colonies formed in soft agar in four independent experiments; data in each experiment were normalized to the number of colonies that formed with the parental K-Ras- $/ \mathrm{cm} \mathrm{t}^{\mathrm{fl} / \mathrm{fl} \mathrm{fx}}$ fibroblasts. Inactivation of $/ \mathrm{cm} t$ significantly reduced the number of colonies that formed in soft $\operatorname{agar}\left({ }^{*} P<0.0001\right)$. For experiments involving K-Ras-Icmt ${ }^{f \mid x / f l x: I C M T}$ cells (expressing a human ICMT $\left.c D N A\right)$ and the derivative K-Ras-Icmt ${ }^{\Delta / \Delta: I C M T}$ cells, data show the results from three independent experiments. In the cells expressing human ICMT, inactivation of mouse $\mathrm{lcm} t$ did not affect colony formation $(P=0.63)$. (c) Western blot showing higher $\mathrm{K}$-Ras expression levels in $\mathrm{K}$-Ras-transfected cells $(+)$ compared with nontransfected cells (-). The blot was stripped and incubated with an anti-Erk1/2 antibody as a loading control. IB, immunoblot.

fected cells to grow in soft agar - except when the cells had been transfected with human ICMT. Similar data were obtained in experiments with fibroblasts from conventional Icmt knockout embryos $\left(\mathrm{Icmt}^{--}\right)$and littermate $\mathrm{Immt}^{+/+}$controls. After immortalization of the fibroblasts and K-Ras transfection, the $\mathrm{Icmt}^{+/+}$fibroblasts, but not the $\mathrm{Icmt} /$ - fibroblasts, formed colonies in soft agar $(n=$ five independent $I c m t /-$ and $n=$ three independent $\mathrm{Icmt}^{+/+}$cell lines) (not shown).

To assess the consequences of Icmt deficiency on tumor cell growth in vivo, mixed populations of K-Ras$I c m t^{\mathrm{fl} x / \mathrm{flx}}$ and K-Ras-Icmt $t^{\Delta / \Delta}$ cells (produced by treating K-Ras-Icmt $\mathrm{fl}^{\mathrm{fl} / \mathrm{fl} x}$ cells with a low titer of AdRSVCre and a high titer of AdRSVnlacZ) were injected subcutaneously into nude mice, and tumors were harvested 21 days later. The ratio of the $I c m t^{\mathrm{flx}}$ band to the Icmt $t^{\Delta}$ band in the injected cell mixture was $1.1 \pm 0.2$, reflecting nearly equal numbers of $I c m t^{\mathrm{fl} x / \mathrm{flx}}$ and Icmt $t^{\Delta / \Delta}$ cells (Figure 4). In the tumors, the ratio of the $I \mathrm{~cm} \mathrm{f}^{\mathrm{fl} x}$ band to the Icm $t^{\Delta}$ band was $15.2 \pm 2.2$ (Figure $4, n=10$ tumors), indicat- ing that it was mainly the $I c m t^{\mathrm{flx} / \mathrm{flx}}$ cells that contributed to tumor growth.

Ras proteins in Icmt ${ }^{\Delta / \Delta}$ cells are mislocalized, but Erk and Akt phosphorylation are unaffected. A GFP-K-Ras fusion protein was mislocalized in Icmt-deficient fibroblasts (Figure 5a). Also, a large portion of the K-Ras in K-Ras$I c m t^{\Delta / \Delta}$ fibroblasts was present in the soluble (S100)
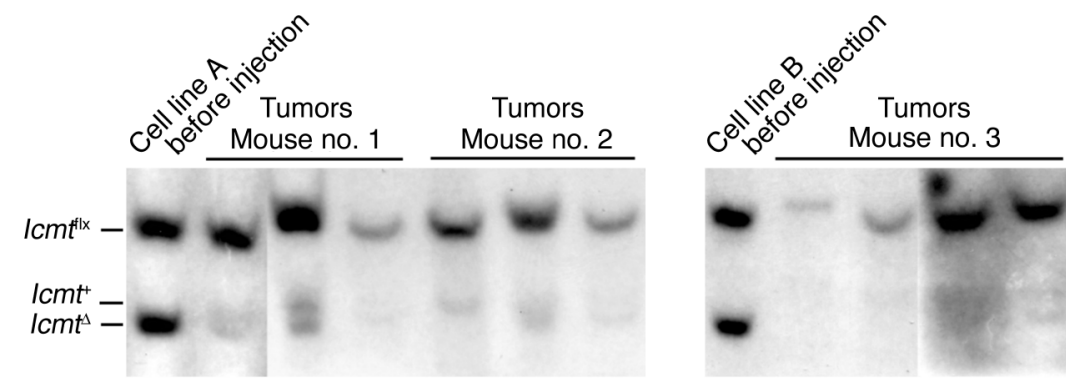

\section{Figure 4}

Impaired ability of K-Ras-transfected Icmt-deficient fibroblasts to contribute to tumor growth in nude mice. A mixed population of K-Ras- $/ \mathrm{cm} t^{\mathrm{fl} / \mathrm{fl} \mid \mathrm{x}}$ cells and derivative K-RasIcmt ${ }^{\Delta / \Delta}$ cells (total of 500,000 cells, prepared as described in the Methods section) was injected subcutaneously into nude mice. Tumors were harvested 21 days later. Southern blots were performed on genomic DNA prepared from the injected cells and the tumors. The ratio of $/ \mathrm{cm} t^{\mathrm{fl} x}$ to $/ \mathrm{cm} t^{\Delta}$ band intensity was much greater in the tumor DNA than in the injected cells. A 5-kb Icmt ${ }^{+}$allele in some lanes was due to host DNA in the tumors. 
a

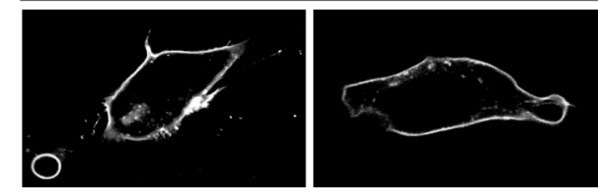

b

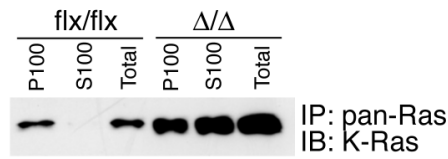

C Cell line A Cell line B Control flxfllx $\Delta / \Delta$ fl|fflx $\Delta / \Delta$ GTP GDP $\longrightarrow$ IP: Raf IB: pan-Ras

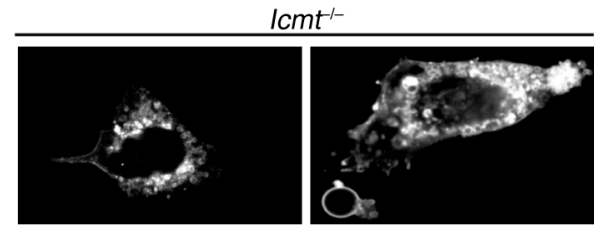

d $f|x / f| x \mid \Delta / \Delta$

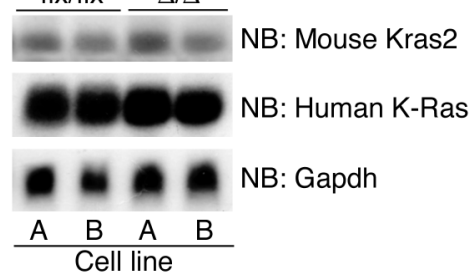

Figure 5

Mislocalization and increased steady-state levels of K-Ras in I cmt-deficient fibroblasts. (a) Confocal micrographs of spontaneously immortalized $/ \mathrm{cmt}^{+/+}$and $/ \mathrm{cmt}^{-/-}$fibroblasts that had been transfected with a GFP-K-Ras fusion construct. (b) Distribution of Ras proteins in the

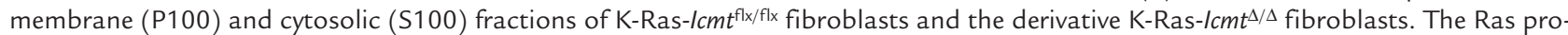
teins were immunoprecipitated from $1,000 \mu \mathrm{g}$ of the indicated cell fractions with a pan-Ras-specific antibody, and a Western blot was performed with a K-Ras-specific antibody. (c) GTP-bound Ras proteins in K-Ras-Icmt $t^{f \mid x / f l x}$ fibroblasts and derivative K-Ras-Icmt ${ }^{\Delta / \Delta}$ fibroblasts. GTP-bound Ras proteins were precipitated from $1 \times 10^{6} \mathrm{~K}$-Ras-Icmt $t^{f|x / f| x}$ and K-Ras-Icmt ${ }^{\Delta / \Delta}$ cells with the Ras-binding domain of Raf (Ras Activation Kit; Upstate Biotechnology Inc.), and a Western blot was performed with a pan-Ras antibody. (d) Northern blot of total RNA from K-Ras-Icmt $t^{f l / f l x}$ and K-Ras-Icmt ${ }^{\Delta / \Delta}$ fibroblasts, hybridized with a mouse Kras2 cDNA probe. That probe detects a longer mouse Kras2 transcript (upper panel) and a shorter human activated K-Ras transcript (middle panel). The blot was stripped and hybridized with a Gapdh cDNA probe (lower panel). IP, immunoprecipitation; NB, Northern blot.

fraction of cells, whereas nearly all of the K-Ras in the parental K-Ras-Icmt $t^{\mathrm{fl} / \mathrm{fl} x}$ fibroblasts was associated with the membrane (P100) fraction (Figure 5b). Notably, inactivation of Icmt in the K-Ras-Icmt $t^{\mathrm{fl} / \mathrm{flx}}$ fibroblasts invariably caused about a twofold increase in steady-state levels of total Ras proteins and GTPbound Ras proteins within cells (Figure 5, b and c), while the ratio of total to GTP-bound Ras remained constant (not shown). The higher levels of the Ras proteins could not be explained by higher levels of mouse K-Ras or human K-Ras mRNA (Figure $5 \mathrm{~d}$ ) and are apparently due to a decreased turnover of Ras in these cells (see later).

The inactivation of Icmt in nontransfected cells (i.e., no activated K-Ras) did not affect serum growth factor-stimulated or EGF-stimulated phosphorylation of the downstream Ras effectors, Erk1/2 and Akt1 (Figure 6 , a and $b$ ). These results indicate that the absence of carboxyl methylation of CAAX proteins in Icmt-defi-

\section{Figure 6}

Growth factor-stimulated Erk1/2 and Akt1 phosphorylation in Icmtdeficient fibroblasts. (a) Nontransfected $/ \mathrm{cm} t^{\mathrm{fl} / \mathrm{fl} \mathrm{x}}$ and the derivative $\mathrm{Icm}^{\Delta / \Delta}$ fibroblasts were seeded at equal density and serum-starved overnight as described in the Methods section. Serum-containing medium was then added to the cells. Cells were harvested at the indicated time points and analyzed by immunoblotting with antibodies against phosphorylated Erk1/2 (p-Erk1/2), phosphorylated Akt1 (p-Akt1), and total Erk1/2. (b) Icmt $t^{f \mid x / f l x}$ and the derivative Icmt $t^{\Delta / \Delta}$ fibroblasts were seeded at equal density and serum-starved overnight. Medium ( $0.5 \%$ serum) supplemented with EGF (50 $\mathrm{ng} / \mathrm{ml}$ ) was added to the cells. Cells were harvested at the indicated time points and analyzed by immunoblotting with antibodies against $\mathrm{p}$-Erk1/2 and total Erk1/2. cient cells has prominent effects on Ras targeting to membranes and on the steady-state levels of Ras proteins in cells, but apparently little or no effect on the growth factor-stimulated activation of Erk $1 / 2$ and Akt. Accelerated turnover of Rho proteins in Icmt ${ }^{\Delta / \Delta}$ fibroblasts. The Rho GTPases play important roles in cell-cycle progression and cell transformation (33-35). Rho proteins are CAAX proteins that, like the Ras proteins, undergo Icmt-mediated methylation. We hypothesized that the slow growth of $I c m t^{\Delta / \Delta}$ fibroblasts and their resistance to K-Ras transformation might be accompanied by a defect in Rho metabolism and signaling. Indeed, our data suggest that this was the case. The steady-state levels of total RhoA and GTP-bound RhoA in K-Ras-Icmt $t^{\Delta / \Delta}$ fibroblasts were only about $5-10 \%$ of those in the parental K-Ras-Icmt $\mathrm{fl}^{\mathrm{fl} / \mathrm{fl} x}$ cells
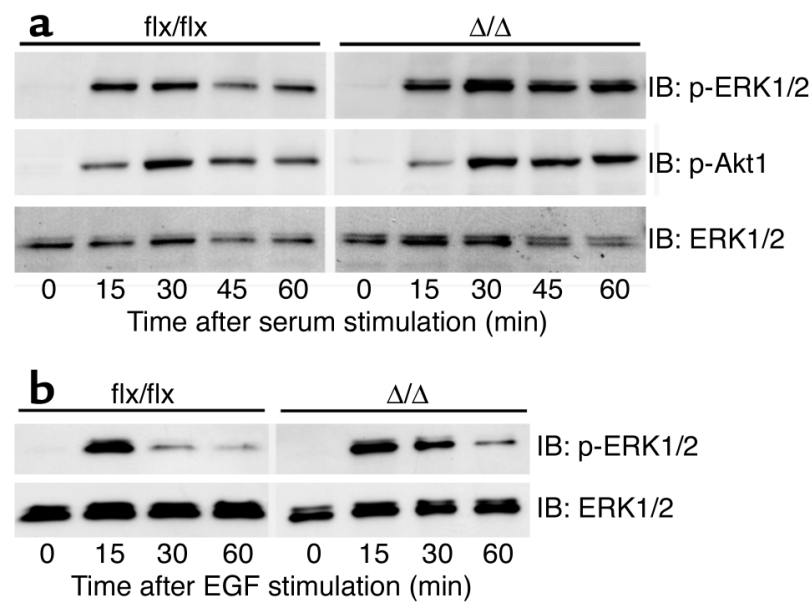


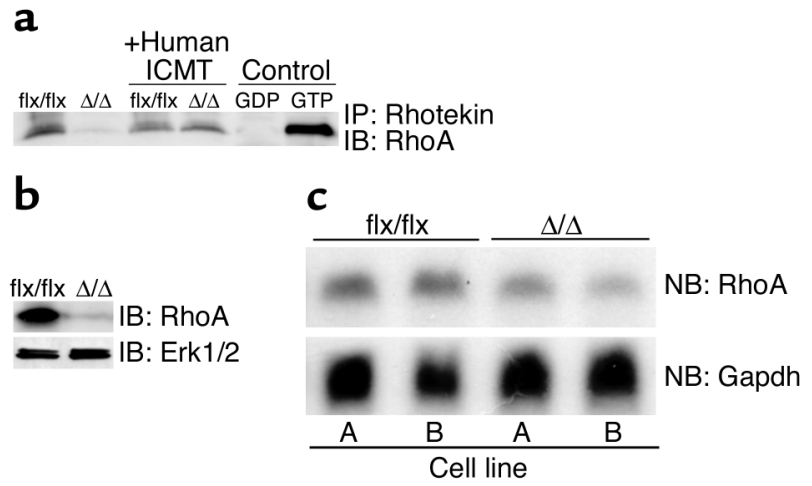

Figure 7

Low steady-state levels of RhoA in Icmt-deficient fibroblasts. (a) GTPbound Rho proteins were immunoprecipitated from $1 \times 10^{6} \mathrm{~K}$-RasIcm $t^{f l \mid f l}$ fibroblasts and derivative K-Ras-Icm $t^{\Delta / \Delta}$ fibroblasts with equal amounts of Rhotekin-GST (Rho Activation Kit; Upstate Biotechnology Inc.). The GTP-bound Rho proteins were resolved by SDS-PAGE and detected with a RhoA-specific antibody (26C4 monoclonal; Santa Cruz Biotechnology Inc.). In the same experiment, bands for two control proteins were of identical intensity in the K-Ras- $/ \mathrm{cm} \mathrm{f}^{\mathrm{fl} \mathrm{f} / \mathrm{flx}}$ and K-Ras- $I \mathrm{~cm} t^{\Delta / \Delta}$ fibroblasts (not shown). Similar results were obtained when using a pan-Rho antibody. (b) Cell extracts from K-Ras-Icmt $t^{\mathrm{fl} / \mathrm{fl} \mathrm{x}}$ fibroblasts and the derivative K-Ras-Icmt ${ }^{\Delta / \Delta}$ fibroblasts were analyzed by immunoblotting with a RhoA-specific antibody. The blot was stripped and incubated with an anti-Erk1/2 antibody as a loading control. (c) Northern blot (NB) of total cellular RNA from K-Ras-Icmt $t^{f \mid x / f l x}$ fibroblasts and the derivative K-Ras-Icmt $t^{\Delta / \Delta}$ fibroblasts was hybridized with a mouse RhoA cDNA probe. Reprobing of the membrane with a Gapdh cDNA probe revealed similar levels of Gapdh expression in each sample (see Figure 5d).

(Figure 7 , a and $\mathrm{b}, P<0.001$ ). This finding was clearly due to absence of Icmt activity, since K-Ras-Icmt ${ }^{\Delta / \Delta}$ fibroblasts expressing the human ICMT cDNA exhibited normal levels of GTP-bound RhoA (Figure 7a). The low levels of RhoA protein in K-Ras-Icmt $t^{\Delta / \Delta}$ fibroblasts were not accompanied by a comparable reduction in the levels of RhoA mRNA (Figure 7c).

To determine if accelerated Rho turnover was responsible for the low levels of RhoA in the K-Ras-Icmt $t^{\Delta / \Delta}$ fibroblasts, we used metabolic labeling/pulse-chase

\section{Figure 8}

Accelerated turnover of Rho proteins in Icmt-deficient fibroblasts. (a) K-Ras- $/ c m t^{f \mathrm{~lx} / \mathrm{flx}}$ and K-Ras-Icmt ${ }^{\Delta / \Delta}$ fibroblasts were labeled with $\left[{ }^{35} \mathrm{~S}\right]$ methionine/cysteine for 2 hours and then incubated in regular medium supplemented with $4 \mathrm{mM}$ "cold" methionine and cysteine for the indicated times. Rho proteins were immunoprecipitated from total cell extracts with a pan-Rho antibody, resolved by SDSPAGE, and then visualized by autoradiography as described in the Methods section. (b) Pulse-chase analysis of Rho protein disappearance in K-Ras-Icmt $t^{\mathrm{fl} / \mathrm{fl} \mathrm{x}}$ and the derivative K-Ras- $/ \mathrm{cm} t^{\Delta / \Delta}$ fibroblasts. Graphs show mean densitometry results from three independent experiments. (c) Pulse-chase analysis of Ras proteins in $\mathrm{K}$-Ras-Icmt $t^{\mathrm{fl} / \mathrm{fl} \mathrm{x}}$ and the derivative K-Ras- $/ \mathrm{cm} t^{\Delta / \Delta}$ fibroblasts. Ras proteins were immunoprecipitated from total cell extracts with a panRas antibody, resolved by SDS-PAGE, and then visualized by autoradiography. Graphs show mean densitometry data from two independent experiments. experiments to assess the half-life of Rho proteins in cells. In four separate experiments, Rho proteins disappeared more quickly in the K-Ras-Icmt $t^{\Delta / \Delta}$ cells than in the parental K-Ras-Icmt $t^{\mathrm{fl} x / \mathrm{fl} x}$ cells (Figure 8, a and b) (Rho half-life, $22.0 \pm 9.4$ hours in K-Ras-Icm $t^{\mathrm{fl} / \mathrm{flx}}$ cells and $2.8 \pm 0.4$ hours in the K-Ras-Icmt $t^{\Delta / \Delta}$ cells). Notably, the absence of methylation retarded Ras turnover within cells (Figure 8c) (Ras half-life, $13.9 \pm 6.1$ hours in K-Ras-Icmt $t^{\mathrm{ll} x / \mathrm{flx}}$ cells and $32.5 \pm 6.0$ hours in K-Ras$\operatorname{Icm} t^{\Delta / \Delta}$ cells), probably explaining the differences in steady-state levels of Ras proteins in Figure 5, b and c. Thus, the absence of carboxyl methylation is associated with accelerated turnover of the Rho proteins but retarded turnover of the Ras proteins.

Upregulation of 21 $^{\text {Cip } 1}$ in K-Ras-transfected Icmt ${ }^{\Delta / \Delta}$ fibroblasts. The regulatory protein $\mathrm{p} 21^{\mathrm{Cip} 1}$ binds to cyclins and inhibits cell-cycle progression $(35,36)$. p $21^{\text {Cip } 1}$ levels are upregulated by overexpression of activated Ras, but this Ras-induced upregulation can be antagonized by RhoA $(32,34)$. In light of the low levels of RhoA in K-RasIcmt $t^{\Delta / \Delta}$ fibroblasts, we hypothesized that those cells

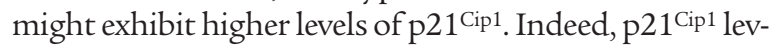
els in K-Ras-Icm $t^{\Delta / \Delta}$ cells were more than fourfold higher in K-Ras-Icmt $t^{\Delta / \Delta}$ cells than in the parental K-Ras-Icmt $t^{\mathrm{fl} / \mathrm{fl} x}$ cells (Figure 9a, $P<0.01$ ). The increase in $\mathrm{p} 21^{\text {Cip } 1}$ protein levels in K-Ras-Icmt $t^{\Delta / \Delta}$ fibroblasts was accompanied by a 1.4-fold increase in $\mathrm{p}^{2} 1^{\mathrm{Cip} 1} \mathrm{mRNA}$ levels (Figure 9b, $P<0.001)$. The increase in $\mathrm{p} 21^{\text {Cip } 1}$ protein levels was not

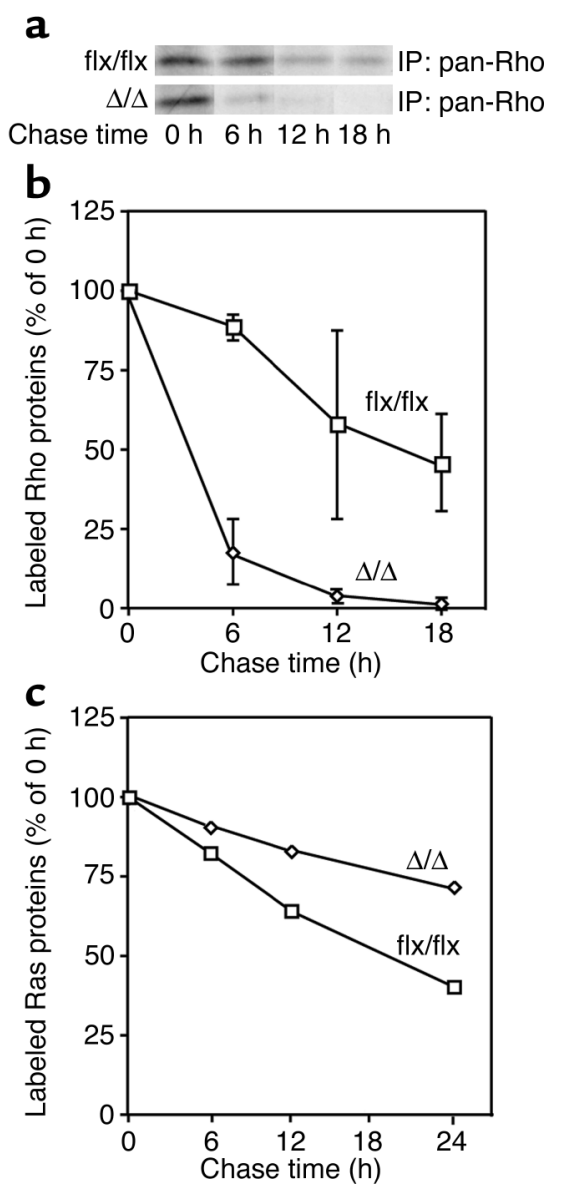


a

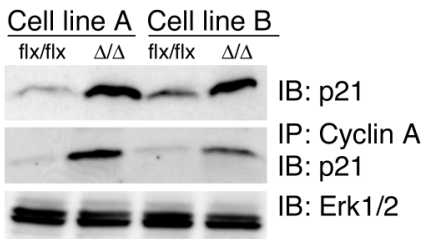

c

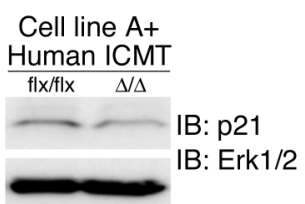

b
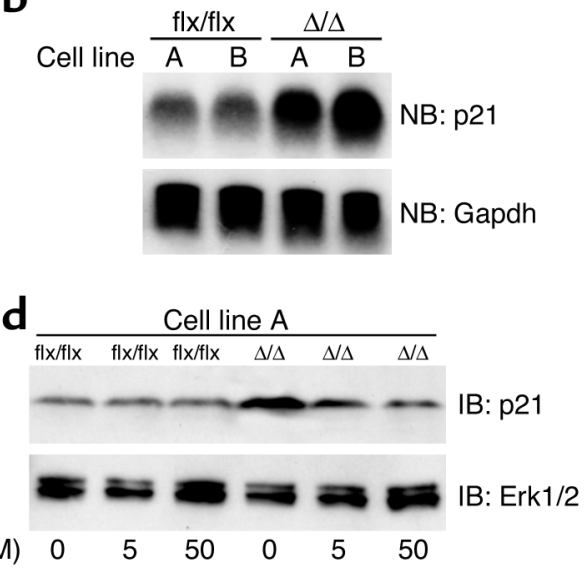

Figure 9

Increased p21Cip1 protein levels in Icmt-deficient fibroblasts. (a) Extracts from K-Ras-Icmt $\mathrm{fl}^{\mathrm{f} / \mathrm{fl} \mathrm{x}}$ and the derivative K-Ras-Icmt $t^{\Delta / \Delta}$ fibroblasts were analyzed by immunoblotting with an antibody recognizing p21Cip1 (F-5 monoclonal; Santa Cruz Biotechnology Inc.) (upper panel). Cyclin A was immunoprecipitated from the cell extracts with a polyclonal antibody (H-432; Santa Cruz Biotechnology Inc.), and cyclin A-associated p $21^{\text {Cip } 1}$ was detected by immunoblotting (middle panel). The blot from the upper panel was stripped and incubated with an anti-Erk $1 / 2$ antibody as a loading control (lower panel). Similar results were obtained in three independent experiments. (b) Northern blot of total cellular RNA showing p21 ${ }^{\mathrm{Cip} 1}$ (Cdkn1a) mRNA levels in K-Ras-Icmt $t^{f l / f l x}$ fibroblasts and the derivative K-Ras-Icmt $t^{\Delta / \Delta}$ fibroblasts (upper panel). The blot was stripped and probed with a Gapdh cDNA probe as a loading control (lower panel). Similar results were obtained in three independent

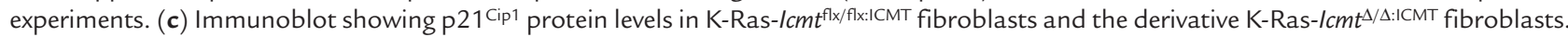
The blot was stripped and incubated with an anti-Erk1/2 antibody as a loading control (lower panel). (d) K-Ras-Icmt $t^{f l} / f \mathrm{~lx}$ and K-Ras-Icmt $t^{\Delta / \Delta}$ fibroblasts were treated overnight with the MEK inhibitor PD98059, and extracts were analyzed by immunoblotting with a p21 Cip1-specific antibody. The blot was stripped and incubated with an anti-Erk1/2 antibody as a loading control (lower panel).

observed in K-Ras-Icmt ${ }^{\Delta / \Delta}$ cells expressing a human ICMT cDNA (Figure 9c). The increased level of p21 Cip1 in K-Ras-Icmt $t^{\Delta / \Delta}$ fibroblasts was accompanied by an increased association between $\mathrm{p} 21^{\text {Cip } 1}$ and cyclin A (Figure 9a, middle panel). To test whether signaling through the Erk1/2 pathway was involved in the upregulation of p21 ${ }^{\text {Cip } 1}$, we treated K-Ras-Icmt $t^{\Delta / \Delta}$ fibroblasts and the parental K-Ras-Icm $t^{\mathrm{fl} \mid / f^{\mathrm{flx}}}$ cells with the MEK inhibitor PD98059. PD98059 decreased p21 Cip1 levels in the K-RasIcmt $t^{\Delta / \Delta}$ fibroblasts, but it did not affect $\mathrm{p} 21^{\mathrm{Cip} 1}$ levels in the K-Ras-Icmt $\mathrm{fl}^{\mathrm{lx} / \mathrm{flx}}$ fibroblasts (Figure 9d). This result does not prove that Ras signaling is involved in the upregulation of $21^{\text {Cip } 1}$. However, in nontransfected Icm $t^{\Delta / \Delta}$ fibroblasts, the levels of $\mathrm{p} 21^{\mathrm{Cip} 1}$ were similar to those in the parental Icm $t^{\mathrm{fl} / \mathrm{fl} x}$ fibroblasts (not shown). These data suggest that increased Ras signaling through the Erk $1 / 2$ pathway could be responsible for the upregulation of $\mathrm{p} 21^{\text {Cip}} 1$ in K-Ras-Icm $t^{\Delta / \Delta}$ fibroblasts.

\section{Figure 10}

Knocking out $21^{\mathrm{Cip} 1}$ restores the capacity of K-Ras-Icmt $\mathrm{t}^{\mathrm{\Delta} / \Delta}$ fibroblasts to grow in soft agar. (a) Western blot showing the absence of p2 $1^{\text {Cip } 1}$ protein in K-Ras- $/ \mathrm{cm} t^{\mathrm{fl} / \mathrm{fl} \mathrm{lx}} \mathrm{Cdkn} 1 \mathrm{a}^{-/-}$fibroblasts and the derivative K-Ras-Icmt ${ }^{\Delta / \Delta} \mathrm{Cdkn1} \mathrm{a}^{-/}$fibroblasts. The blot was stripped and incubated with an anti-Erk1/2 antibody as a loading control (lower

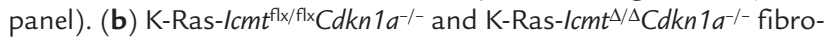
blasts were seeded in soft agar. After 30 days, the colonies were stained, photographed, and analyzed as described in the Methods section. Similar results were obtained in three independent experiments; there

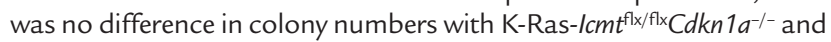
the derivative K-Ras-Icmt ${ }^{\Delta / \Delta} C d k n 1 a^{-/-}$fibroblasts $(P=0.47)$.
Knocking out $p 21^{\text {Cip } 1}$ restores the capacity of K-Ras-transfected Icmt $t^{\Delta / \Delta}$ fibroblasts to grow in soft agar. The finding that $\mathrm{p} 21^{\text {Cip } 1}$ levels were elevated in K-Ras-Icmt ${ }^{\Delta / \Delta}$ fibroblasts suggested that $\mathrm{p} 21^{\mathrm{Cip} 1}$ might be important for the markedly reduced oncogenic capacity of these cells. To test this hypothesis, we generated p21 Cip1-deficient K-Ras-Icmt $t^{\mathrm{fl} / \mathrm{fl} \mathrm{x}}$ fibroblasts and then used AdRSVCre to produce $\mathrm{p} 21^{\text {Cip } 1-d e f i c i e n t ~ K-R a s-I c m t ~} t^{\Delta / \Delta}$ fibroblasts (Figure 10a). In the absence of p 21 Cip1, the inactivation of Icmt no longer blocked the ability of K-Ras-transfected cells to grow in soft agar (Figure 10b). Similarly,

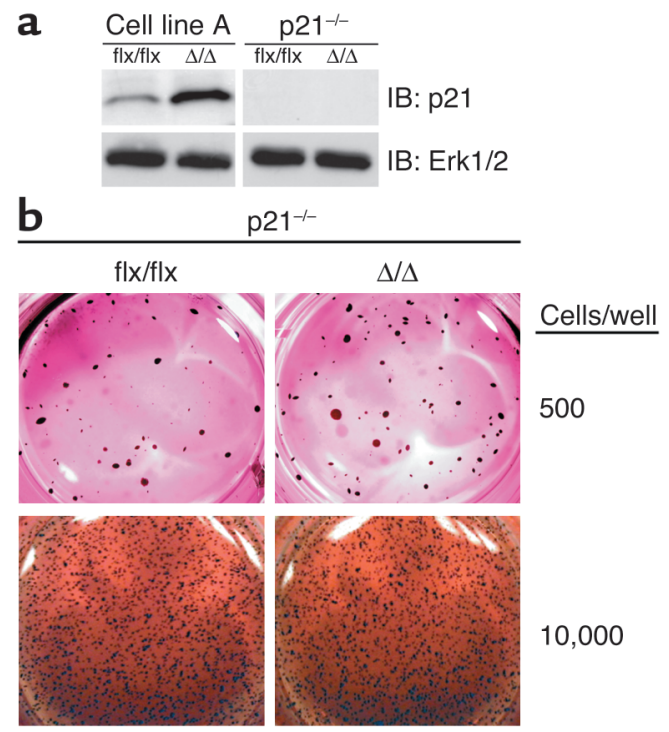




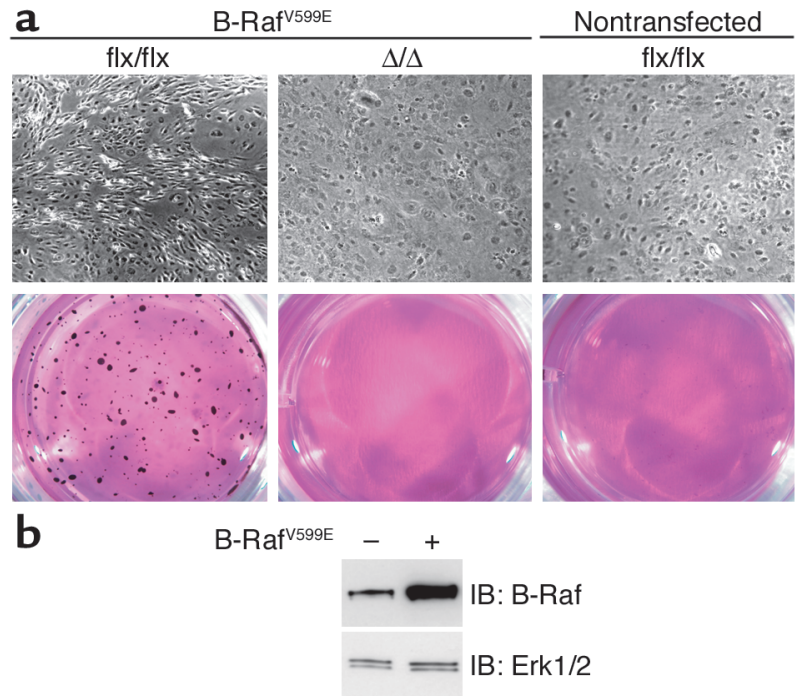

\section{Figure 11}

Inactivation of $/ \mathrm{cm}$ t reverses B-Raf-induced transformation. (a) B-RafIcm $t^{\mathrm{fl} / \mathrm{fl} \text { a }}$ and B-Raf-Icmt $t^{\Delta / \Delta}$ fibroblasts were grown to confluence and then allowed to grow for an additional 6 days. The cells were then fixed in $4 \%$ paraformaldehyde and photographed (upper panel). An aliquot of the same cells was seeded in soft agar (lower panel). After 20 days, the colonies were stained, photographed, and analyzed as described in the Methods section. Similar results were obtained in three independent experiments. Transfection of fibroblasts with a retrovirus encoding wild-type B-Raf did not yield a transformed phenotype (not shown). (b) Western blot with a B-Raf-specific mAb (F-7; Santa Cruz Biotechnology Inc.) showing increased B-Raf expression in $1 \mathrm{~cm} \mathrm{t}^{\mathrm{fl} / \mathrm{fl} \mathrm{f}}$ fibroblasts transfected with the retrovirus encoding human B-Raf $\mathrm{V} 599 \mathrm{E}$. The blot was stripped and incubated with an antiErk1/2 antibody as a loading control (lower panel).

in the absence of $\mathrm{p} 21^{\mathrm{Cip}}{ }^{1}$, there was no difference in the growth rate of K-Ras-Icmt $t^{\Delta / \Delta}$ and K-Ras-Icmt $t^{\mathrm{flx} / \mathrm{flx}}$ fibroblasts under routine cell-culture conditions (anchorage-dependent growth) (not shown).

Inactivation of Icmt blocks B-Raf-induced cellular transformation. To determine if the effect of the Icmt inactivation was limited to inhibiting the growth of K-Rastransformed fibroblasts, we analyzed the effect of inactivating Icmt in $I c m t^{\mathrm{fl} \times / \mathrm{flx}}$ cells that had been infected with a retrovirus encoding a mutationally activated form of human B-Raf (V599E). B-Raf-Icm $\mathrm{fl}^{\mathrm{fl} / \mathrm{flx}}$ fibroblasts grew faster than nontransfected cells, lost contact inhibition, and were capable of forming colonies in soft agar (Figure 11). AdRSVCre-mediated deletion of Icmt from B-Raf-Icm $t^{\mathrm{fl} / \mathrm{fl} \mathrm{l}}$ fibroblasts (to produce B-Raf-Icm $t^{\Delta / \Delta}$ fibroblasts) restored contact inhibition and eliminated the ability of the cells to grow in soft agar (Figure 11). In addition, B-Raf-transfected Icmt/fibroblasts did not form colonies in soft agar, whereas B-Raf-transfected $\mathrm{Immt}^{+/+}$fibroblasts did (not shown).

\section{Discussion}

In the current study, we show that inactivation of Icmt in mouse fibroblasts results in slow growth and a striking reduction in oncogenic transformation induced by
K-Ras and B-Raf. For the K-Ras-transfected fibroblasts we also provide evidence that the absence of carboxyl methylation results in a rapid turnover of RhoA and an upregulation of the cyclin-dependent kinase inhibitor p21 Cip1. These phenotypes were abrogated by the ectopic expression of a human ICMT cDNA. In addition, the finding that deletion of Cdkn1a (the gene encoding p21 Cip $1^{1}$ abolished the effects of the Icmt inactivation on cell growth and K-Ras-induced colony formation in soft agar, suggests that the Icmt knockout-mediated inhibition of cell growth and K-Ras transformation requires $\mathrm{p} 21^{\text {Cip } 1}$.

Cre-mediated inactivation of Icmt caused a 90-95\% reduction in K-Ras-induced colony growth in soft agar and a reduced capacity to contribute to tumor growth in nude mice. This phenotype is almost certainly due to inactivation of Icmt rather than to an artifact related to adenoviral infection-for several reasons. First, all of the control cells for these experiments were treated with an adenovirus encoding $\beta$-gal. Second, the adenovirus treatment was temporally remote from the actual experiments; all of the transformation experiments were performed at least three or four passages-more than 20 cell divisions-after adenoviral infection. Third, Cre-mediated inactivation of Icmt had no detectable effects in cells that had been previously transfected with a cDNA encoding human ICMT. Fourth, we obtained very similar cell growth and transformation results with conventional Icmt-knockout fibroblasts (Icmt $t^{-1}$ cells), which were not treated with adenovirus. Finally, we previously showed that Cre-adenovirus infection, under the conditions used here, did not change the growth rate of fibroblasts (21).

It is widely believed that targeting of Ras proteins to the plasma membrane is very important for downstream signaling cascades. Icmt deficiency caused a striking mislocalization of GFP-K-Ras away from the plasma membrane, as well as a redistribution of Ras proteins to the cytosolic fraction. However, the mislocalization of K-Ras was not accompanied by detectable decreases in growth factor-stimulated activation of Erk1/2 and Akt1. We have made identical observations in Rce1-deficient cells-a striking mislocalization of Ras proteins (21) but no apparent effect on Erk1/2 signaling (E. Kim et al., unpublished observations). We do not yet fully understand why the mislocalization of Ras proteins is not accompanied by detectable changes in signaling, but several possibilities exist. First, growth factor stimulation of Erk1/2 and Akt1 in Icmt-deficient cells may simply be mediated by non-Ras pathways. Second, it is possible that a small percentage of the Ras proteins make it to the plasma membrane in Icmt-deficient cells and that this small amount of normally targeted Ras is sufficient for the signaling "readouts". Another possibility is that some of the Ras proteins in Icmt-deficient cells are mislocalized to the Golgi or ER membranes and that signaling occurs fairly normally from those locations. This explanation is not farfetched. It was recently shown that Ras targeted to the 
Golgi or ER was able to recruit Raf-1, activate the Erk pathway, and transform fibroblasts (37).

The fact that growth factor-stimulated Erk1/2 and Akt signaling was normal in the setting of Icmt deficiency prompted us to seek other explanations for the retarded cell growth and the reduced capacity of K-Ras-transfected cells to form colonies in soft agar. The Rho proteins are required for Ras transformation and are sometimes found at increased concentrations in Ras-transformed cells $(35,38)$. Because the Rho proteins are also substrates for Icmt, we asked whether Icmt deficiency might perturb Rho metabolism. Indeed, this was the case. The steadystate levels of GTP-bound RhoA and total RhoA were lower in the $I c m t^{\Delta / \Delta}$ fibroblasts than in the parental $I c m t^{\mathrm{flx} / \mathrm{flx}}$ cells, as a result of accelerated protein turnover. These findings were consistent with earlier results from Backlund (39). He used a combination of pulse-chase studies and two-dimensional gel electrophoresis to show that nonmethylated RhoA is less stable than the methylated form. Notably, the effect of methylation on protein stability can be very different for other CAAX proteins; the Ras proteins in $I c m t^{\Delta / \Delta}$ cells were actually more stable than the Ras proteins in Icmt $t^{\mathrm{fl} x / \mathrm{fl} x}$ cells. In the case of the Ras proteins, one might reasonably hypothesize that normal Ras turnover occurs only at certain membrane surfaces, and that changes in Ras partitioning within the cell would have secondary effects on protein degradation. The finding of increased Ras levels is consistent with data from Holstein et al. (40). They found that Ras protein levels increase after mevalonate depletion, which inhibits isoprenylation of CAAX proteins. However, in their experiments, RhoA protein levels also increased. Thus, isoprenylation and carboxylmethylation could have opposite effects on the steady-state levels of RhoA.

Data from Olson et al. (36) suggest that constitutive Ras signaling in the absence of Rho increases $\mathrm{p} 21^{\text {Cip } 1}$ levels, leading to cell-cycle arrest. Microinjection of activated Ras into fibroblasts increased DNA synthesis, whereas the simultaneous microinjection of Ras and a specific Rho inhibitor (C3 exoenzyme) increased p21 ${ }^{\text {Cip } 1}$ and inhibited DNA synthesis (36). In our studies, the inactivation of Icmt in K-Ras-transfected fibroblasts was associated with a striking reduction in RhoA protein levels and a 4.2-fold upregulation of $\mathrm{p} 21^{\mathrm{Cip} 1}$. We predicted that the upregulation of $\mathrm{p} 21^{\mathrm{Cip} 1}$ might be an important influence in the reduced capacity of Icmt-deficient fibroblasts to grow in soft agar. Indeed, this seemed to be the case. When we performed experiments with K-Ras-Icmt $t^{\mathrm{flx} / \mathrm{flx}}$ cells lacking p21 ${ }^{\mathrm{Cip} 1}$

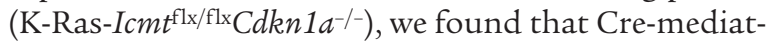
ed inactivation of Icmt had no measurable effect on cell growth on plastic plates or on the growth of colonies in soft agar. Notably, both FTase inhibitors and GGTase I inhibitors have been reported to increase p21 ${ }^{\text {Cip } 1}$ levels in human tumor cells $(41,42)$.

Our results indicate that the effect of the Icmt inactivation on K-Ras transformation may have been a consequence of its effects on Rho and $\mathrm{p} 21^{\text {Cip } 1}$ rather than being due to a direct effect on the intrinsic prop- erties of K-Ras itself. To explore this issue further, we examined the consequences of inactivating Icmt in cells that had been transformed with mutationally activated B-Raf, a downstream Ras effector. Activating mutations in B-Raf have been identified in $66 \%$ of malignant melanomas (43). B-Raf is not a CAAX protein and hence not a substrate for Icmt, yet the Cremediated inactivation of Icmt reversed the transformed phenotypes in B-Raf-transfected cells. This finding is in keeping with the notion that the reversion of K-Ras transformation may not have been due to a direct effect on K-Ras.

The current study supports the idea that Icmt could be a therapeutic target for treating cancer. Perhaps more importantly, however, the current study has created a tool for addressing this issue. With the creation of mice harboring a conditional Icmt allele, it is now possible to test whether a deficiency in Icmt would retard tumor growth in vivo. Several groups have developed "latent oncogenes" that can be activated in vivo by expressing Cre, resulting in the formation of tumors $(44,45)$. In those mice, it would be of value to determine if the Cre-induced tumor development could be prevented by the simultaneous inactivation of Icmt.

\section{Acknowledgments}

We thank A. Balmain for the Cdkn1 $a^{-/-}$mice, J. Otto for recombinant K-Ras, and G. Howard and S. Ordway for comments on the manuscript. We also thank P.A. Ambroziak, A. George, and C. Gregory for technical assistance during the early stages of this work. This work was supported in part by NIH grants HL41633, RO1 CA099506, and RO1 AR050200 (to S.G. Young), grants from the University of California Tobacco-Related Disease Research Program (to M.O. Bergo and S.G. Young), and the Swedish STINT Foundation (to M.O. Bergo).

1. Casey, P.J., and Seabra, M.C. 1996. Protein prenyltransferases. J. Biol. Chem. 271:5289-5292.

2. Boyartchuk, V.L., Ashby, M.N., and Rine, J. 1997. Modulation of Ras and a-factor function by carboxyl-terminal proteolysis. Science. 275:1796-1800

3. Dai, Q., et al. 1998. Mammalian prenylcysteine carboxyl methyltransferase is in the endoplasmic reticulum. J. Biol. Chem. 273:15030-15034.

4. Goodman, L.E., et al. 1990. Mutants of Saccharomyces cerevisiae defective in the farnesylation of Ras proteins. Proc. Natl. Acad. Sci. U. S. A. 87:9665-9669.

5. Reiss, Y., Goldstein, J.L., Seabra, M.C., Casey, P.J., and Brown, M.S. 1990. Inhibition of purified p21 ras farnesyl:protein transferase by Cys-AAX tetrapeptides. Cell. 62:81-88.

6. Young, S.G., Ambroziak, P., Kim, E., and Clarke, S. 2000. Postisoprenylation protein processing: $\mathrm{C}^{\prime}(\mathrm{CaaX})$ endoproteases and isoprenylcysteine carboxyl methyltransferase. In The enzymes. Volume 21. F. Tamanoi and D.S. Sigman, editors. Academic Press. San Diego, California, USA. 155-213.

7. Bos, J.L. 1989. ras oncogenes in human cancer: a review. Cancer Res. 49:4682-4689.

8. Downward, J. 2003. Targeting RAS signalling pathways in cancer therapy. Nat. Rev. Cancer. 3:11-22.

9. Kato, K., et al. 1992. Isoprenoid addition to Ras protein is the critical modification for its membrane association and transforming activity. Proc. Natl. Acad. Sci. U. S. A. 89:6403-6407.

10. Kohl, N.E., et al. 1995. Inhibition of farnesyltransferase induces regression of mammary and salivary carcinomas in ras transgenic mice. Nat. Med. 1:792-797.

11. Omer, C.A., et al. 2000. Mouse mammary tumor virus-Ki-rasB transgenic mice develop mammary carcinomas that can be growth-inhibited by a farnesyl:protein transferase inhibitor. Cancer Res. 60:2680-2688. 
12. Ashar, H.R., et al. 2001. The farnesyl transferase inhibitor SCH 66336 induces a $\mathrm{G}_{2} \rightarrow \mathrm{M}$ or $\mathrm{G}_{1}$ pause in sensitive human tumor cell lines. Exp. Cell Res. 262:17-27.

13. Sebti, S.M., and Hamilton, A.D. 2000. Farnesyltransferase and geranylgeranyltransferase I inhibitors and cancer therapy: lessons from mechanism and bench-to-bedside translational studies. Oncogene. 19:6584-6593

14. Cox, A.D. 2001. Farnesyltransferase inhibitors. Potential role in the treatment of cancer. Drugs. 61:723-732.

15. Gibbs, J.B., et al. 1997. Farnesyltransferase inhibitors versus Ras inhibitors. Curr. Opin. Chem. Biol. 1:197-203.

16. Oliff, A. 1999. Farnesyltransferase inhibitors: targeting the molecular basis of cancer. Biochim. Biophys. Acta. 1423:C19-C30.

17. Tamanoi, F. 1993. Inhibitors of Ras farnesyltransferases. Trends Biochem. Sci. 18:349-353.

18. James, G., Goldstein, J.L., and Brown, M.S. 1996. Resistance of K-RasB ${ }^{\text {V12 }}$ proteins to farnesyltransferase inhibitors in Rat1 cells. Proc. Natl. Acad. Sci.U. S. A. 93:4454-4458.

19. Whyte, D.B., et al. 1997. K- and N-Ras are geranylgeranylated in cells treated with farnesyl protein transferase inhibitors. J. Biol. Chem. 272:14459-14464.

20. Kim, E., et al. 1999. Disruption of the mouse Rce1 gene results in defective Ras processing and mislocalization of Ras within cells. J. Biol. Chem. 274:8383-8390

21. Bergo, M.O., et al. 2002. Absence of the CAAX endoprotease Rce1: Effects on cell growth and transformation. Mol. Cell. Biol. 22:171-181.

22. Bergo, M.O., et al. 2001. Isoprenylcysteine carboxyl methyltransferase deficiency in mice. J. Biol. Chem. 276:5841-5845.

23. Lin, X., et al. 2002. Prenylcysteine carboxylmethyltransferase is essential for the earliest stages of liver development in mice. Gastroenterology. 123:345-351.

24. Bergo, M.O., et al. 2000. Targeted inactivation of the isoprenylcysteine carboxyl methyltransferase gene causes mislocalization of K-Ras in mammalian cells. J. Biol. Chem. 275:17605-17610.

25. Hanks, M., Wurst, W., Anson-Cartwright, L., Auerbach, A.B., and Joyner, A.L. 1995. Rescue of the En-1 mutant phenotype by replacement of En-1 with En-2. Science. 269:679-682.

26. Todaro, G.J., and Green, H. 1963. Quantitative studies of the growth of mouse embryo cells in culture and their development into established lines. J. Cell Biol. 17:299-313.

27. Zindy, F., et al. 1998. Myc signaling via the ARF tumor suppressor regulates p53-dependent apoptosis and immortalization. Genes Dev. 12:2424-2433.

28. Kelekar, A., and Cole, M.D. 1986. Tumorigenicity of fibroblast lines expressing the adenovirus E1a, cellular p53, or normal c-myc genes. Mol. Cell. Biol. 6:7-14.
29. Kühn, R., Schwenk, F., Aguet, M., and Rajewsky, K. 1995. Inducible gene targeting in mice. Science. 269:1427-1429.

30. Webber, E.M., Wu, J.C., Wang, L., Merlino, G., and Fausto, N. 1994. Overexpression of transforming growth factor- $\alpha$ causes liver enlargement and increased hepatocyte proliferation in transgenic mice. Am. J. Pathol. 145:398-408.

31. Brown, T. 1993. Analysis of RNA by northern and slot blot hybridization. In Current protocols in molecular biology. Volume 1. F.M. Ausubel et al., editors. John Wiley \& Sons. New York, New York, USA. 4.9.1-4.9.14.

32. Brugarolas, J., et al. 1995. Radiation-induced cell cycle arrest is compromised by 21 deficiency. Nature. 377:552-557.

33. McCormick, F. 1998. Signal transduction: why Ras needs Rho. Nature. 394:220-221

34. Pruitt, K., and Der, C.J. 2001. Ras and Rho regulation of the cell cycle and oncogenesis. Cancer Lett. 171:1-10.

35. Sahai, E., Olson, M.F., and Marshall, C.J. 2001. Cross-talk between Ras and Rho signalling pathways in transformation favours proliferation and increased motility. EMBOJ. 20:755-766.

36. Olson, M.F., Paterson, H.F., and Marshall, C.J. 1998. Signals from Ras and Rho GTPases interact to regulate expression of $\mathrm{p} 21^{\text {Waf1/Cip1 }}$. Nature. 394:295-299.

37. Chiu, V.K., et al. 2002. Ras signalling on the endoplasmic reticulum and the Golgi. Nat. Cell Biol. 4:343-350.

38. Zohn, I.M., Campbell, S.L., Khosravi-Far, R., Rossman, K.L., and Der, C.J. 1998. Rho family proteins and Ras transformation: the RHOad less traveled gets congested. Oncogene. 17:1415-1438.

39. Backlund, P.S., Jr. 1997. Post-translational processing of RhoA. Carboxyl methylation of the carboxyl-terminal prenylcysteine increases the halflife of RhoA. J. Biol. Chem. 272:33175-33180.

40. Holstein, S.A., Wohlford-Lenane, C.L., and Hohl, R.J. 2002. Consequences of mevalonate depletion. Differential transcriptional, translational, and post-translational up-regulation of Ras, Rap1a, RhoA, and RhoB. J. Biol. Chem. 277:10678-10682.

41. Sepp-Lorenzino, L., and Rosen, N. 1998. A farnesyl-protein transferase inhibitor induces $\mathrm{p} 21$ expression and $\mathrm{G}_{1}$ block in $\mathrm{p} 53$ wild type tumor cells. J. Biol. Chem. 273:20243-20251.

42. Vogt, A., Sun, J., Qian, Y., Hamilton, A.D., and Sebti, S.M. 1997. The geranylgeranyltransferase-I inhibitor GGTI-298 arrests human tumor cells in $\mathrm{G}_{0} / \mathrm{G}_{1}$ and induces $\mathrm{p} 21^{\mathrm{WAF} 1 / \mathrm{CIP} 1 / \mathrm{SDI} 1}$ in a $\mathrm{p} 53$-independent manner. J. Biol. Chem. 272:27224-27229.

43. Davies, H., et al. 2002. Mutations of the BRAF gene in human cancer Nature. 417:949-954.

44. Lakso, M., et al. 1992. Targeted oncogene activation by site-specific recombination in transgenic mice. Proc. Natl. Acad. Sci. U. S. A. 89:6232-6236.

45. Jackson, E.L., et al. 2001. Analysis of lung tumor initiation and progression using conditional expression of oncogenic K-ras. Genes Dev. 15:3243-3248. 